\title{
The Effects of Organizational Behavior and Activities in the Field of Innovation, Market-Orientation, and Competitor Orientation on Competitive Advantages in Services Industry
}

Fatemeh Bayat* and Karim hamdi

Department of Management, Islamic Azad University, Tehran North Branch, Tehran, Iran

\begin{abstract}
Today, actions and behavior of firms in competitive markets play a significant and effective role in endeavors for building competitive advantages. This is very evident in service oriented industries, such as insurance industry. Meanwhile, organizational endeavors are considered in three directions in this research, which include market-orientation, competitororientation, and innovation-orientation. The main objective of this study is to assess the effectiveness of organizational endeavors in the areas of innovation, competition and market orientation on building competitive advantages. The research method here is applied for the goal and survey for the descriptive nature. The statistical population of this research is the Staff of Saman Insurance branch. The number of people who participated in this research is 319 persons according to the Census Bureau of Saman Insurance. The researcher has used simple random sampling method to select the study sample these people, and the number of respondents people is determined by Cochran sampling formula to be as equal to 174 persons. A 24-question survey is used to collect data, and the validity and reliability of it is approved by the supervisor and adviser in advance. Data analysis software used in this research is Smart PLS. Results show that market-orientation, innovation-orientation and competitive-orientation does do have effect on competitive advantage building.
\end{abstract}

Keywords: Market-orientation; Innovation-orientation; Competitive-orientation; Competitive advantage building

\section{Introduction}

Today, all companies, regardless of their field of activities (both manufacturing and services) need to provide more value to their customers in order to survive and succeed in this rapidly changing and evolving world. Providing more value is possible through creation of sustainable competitive advantage. Creating sustainable competitive advantage in service sector requires effective design and development of strategic resources. Previously, most companies had this impression that quick response to the needs of market and customers will result in greater competitive advantage compared to competitors. However, today this mere concentration on such market-oriented actions is considered as a threat for innovation which will certainly increase company's risks. Since this type of marketing neglects unstated needs of customers, it will not do any help in providing distinct products against competitors. Therefore, only those companies that utilize all their available resources and create clear strategies for building competitive advantages will succeed. So, for insurance companies, such as Saman Insurance, to succeed in competitive market and improve their performance, it's required to properly leverage their resources and capabilities for growth. In this section, the researcher will express the main concern of this study, and discuss goals and assumptions. In other words, in this section, the goal of researcher is to provide an overview of the research.

\section{Problem Statement}

Today, all companies, regardless of their field of activities (both manufacturing and services) need to provide more value to their customers in order to survive and succeed in this rapidly changing and evolving world. Providing more value is possible through creation of sustainable competitive advantage. Creating sustainable competitive advantage in service sector requires effective design and development of strategic resources. Previously, most companies had this impression that quick response to the needs of market and customers will result in greater competitive advantage compared to competitors. However, today this mere concentration on such market-oriented actions is considered as a threat for innovation which will certainly increase company's risks. Since this type of marketing neglects unstated needs of customers, it will not do any help in providing distinct products against competitors. Therefore, only those companies that utilize all their available resources and create clear strategies for building competitive advantages will succeed. So, for insurance companies, such as Saman Insurance, to succeed in competitive market and improve their performance, it's required to properly leverage their resources and capabilities for growth.

Services are one of the most important sectors of the economy that have a high growth. Many companies and programmers are trying to focus on services rather than products in order to increase value creation by Grunus and Vioma, Vergo and Laske, Vitreys et al. showed that more than half of the growth in the service industry sector is related to insurance and banking companies. In 2006, Sheth et al. identified some of the growth factors in this sector of the service industry, which include the intensity of competition in this area, the use of new technologies in improving services, and facilitating entry into the industry. According to the above, investing in this area-serviceoriented companies-can offer more profit and productivity, compared to manufacturing industrial products. The main issue in the service industry is the intensity of competition and communication networks in this industry. In addition to that, designing and innovating services

*Corresponding author: Fatemeh Bayat, Department of Management, Islamic Azad University, Tehran North Branch, Tehran, Iran, Tel: + 00989331290604 E-mail: bayat_fatemeh1396@yahoo.com

Received August 22, 2017; Accepted September 01, 2017; Published September 05, 2017

Citation: Bayat F, Hamdi K (2017) The Effects of Organizational Behavior and Activities in the Field of Innovation, Market-Orientation, and Competitor Orientation on Competitive Advantages in Services Industry. Review Pub Administration Manag 5: 222. doi:10.4172/2315-7844.1000222

Copyright: $\odot 2017$ Bayat F, et al. This is an open-access article distributed under the terms of the Creative Commons Attribution License, which permits unrestricted use, distribution, and reproduction in any medium, provided the original author and source are credited. 
provided, supporting services, monitoring competitors, and applying applied knowledge can be one of the most important problems and issues for the companies active in this field. Insurance companies, because they are active in this field, have problems and issues of this kind. The intensity of competition in the insurance market has made the environment of this industry more complicated and the activities of organizations and companies in this field are more sensitive. If companies do not show a higher rate of response to the variable environment, they will be faced with declining performance due to backwardness. The unknown aspect of this research is what extent of innovation, marketing, and network communication can create a good context for the benefit of the companies. In other words, the research identifies what new steps should be taken by companies to be able to identify themselves as a market leader in competitive markets and gain a high market share. The results of various researches have shown that corporate actions in environmental analysis can offer a good basis for a better understanding of the actions of customers and competitors and their approaches in the market for many companies by Olmia, Uluson et al. Many leading companies try to make different parts of the organization and company interact with the surrounding environment through adopting appropriate environmental strategies, for the purpose of obtaining useful information and knowledge and providing appropriate services in the markets and attracting customers. Of course, the acquisition of applied knowledge requires high patience and tolerance in communication networks between customers and partners and competitors in service markets. The more the acquisition of customer knowledge is suited to the market requirements, the better it will provide the ground for providing appropriate services with innovation and higher success rates for the organizations, and will provide the ground for increasing and improving the competitive position in the market. In this regard, Saman insurance is one of the service companies operating in competitive markets. Please state where it operates. The competition in the insurance industry is very intense due to the activity of public and private sectors, and this has led to a lack of attention to market requirements and reduced the ability of Saman insurance to compete with other companies. And it will become a small market rather than a high share in the insurance industry, and will drastically reduce its competitive performance. Over the past few years that Saman Insurance has entered the industry, it has been successful in this field, but has not yet been able to become one of the most influential companies in the industry, which has led the researcher to believe that the main reason for the failure of Saman's insurance in achieving its organizational missions and acquiring a competitive position is in the market behavioral categories and in providing services with distinct innovation over competitors, and lack of attention to marketing concepts and communication networks with its partners. This means that the strategic approach of the company in the field of market has not been able to function as a competitive advantage.

Therefore, the main issue of the present research is the lack of strategic approach, and the behaviors and actions of Saman insurance company in improving innovation, marketing and communication networks with competitors to improve the competitive advantage of the company. The main question of this research is the extent to which the organization's actions and behaviors in the field of innovation, marketing and communication networks can provide the basis for advantage building performance in Saman insurance.

\section{Theoretical Foundations}

\section{Innovation orientation}

Willingness to innovate is a strategic behavior which provides an open and active opportunity for new ideas to flourish as well as searching for such ideas. Willingness to innovate also shows a knowledge structure that results in understanding the market dynamics and provides a knowledge pattern for developing required procedures and creating dynamic capabilities for companies [1].

\section{Market orientation}

Organizational culture is essential to effectively and efficiently guide individual's behaviors in order to create greater values for customers and improve business functions of the company. In other words, market orientation is to create market awareness in order to predict current and future needs of customers, with the aim of distributing this insight in all organization units and responding to it. This concept further concentrates on gathering, distributing, and applying information as well as effectively serving the needs and demands of consumers [2].

\section{Competitor orientation}

Competitor orientation refers to considering competitors, building bridges with them, and being prepared for dealing with their activities in competitive markets.

\section{Advantage building performance}

Advantage building performance refers to conducting organizational tasks in target markets in order to improve its competitive position. The most famous performance definition is offered by Nili et al. "Procedure of defining the quality of effectiveness and efficiency of old actions in the target market."

\section{Research Methodology}

In this study, the researcher sought to use the results in the shortterm and in the organization industry. Therefore, the current study is an applied research in terms of goals, and the method is surveydescriptive. Because in addition to describing the reality, it analyzes the relationships between variables by testing the hypotheses and tries to determine the impact of variables on each other. The independent variable in this study is organizational performances (competitor orientation, market orientation, and innovation orientation) and the dependent variable is the competitive advantage building.

\section{Statistical population}

Statistical population of the study consist of a collection of individuals and entities who have at least one common attribute [3] and the researcher is interested to relate its study and research findings to the statistical population [4]. The statistical population of this study is the employees of Saman Insurance branch. The number of people is 319 according to the Insurance census bureau. Isn't it 1995, 1991, ert?

\section{Samples and sampling method}

In this research, the researcher has chosen the simple random sampling method to select samples. The reason for choosing this method is, firstly due to the higher similarities between the samples and population, and secondly, the availability of all the members of the population [4].

In this study, the researcher determined sample size according to Cochran formula.

$$
n=\frac{N z^{2} \alpha / 2 p(1-p)}{(N-1) d^{2}+Z^{2} \alpha / 2 p(1-p)}
$$


$\mathrm{n}=$ minimum required sample size

$\mathrm{N}=$ Sample size (319 persons in this research)

$\mathrm{p}=$ distribution of attribute in population

$\mathrm{za} / 2=$ value obtained from the standard normal distribution Table (in this research, considering 0.05 error, value obtained from the standard normal distribution Table is 1.96)

$\mathrm{d}=$ approved error or tolerable range of parameter estimation (in social studies is usually 0.05 )

A necessary point to mention here about this formula is that if the value of $p$ is not accessible, we can use 0.5 instead. In this case, the formula will give the largest and most conservative number. In this research, the value adopted is 0.5 .

Thus, the minimum sample size will be

$$
n=\frac{(319)(1.96)^{2}(0.5)(1-0.5)}{(319-1)(0.05)^{2}+(1.96)^{2}(0.5)(1-0.5)}=174
$$

Thus, at least 174 surveys need to be distributed among samples.

\section{Data collection tools}

Considering the research methodology which is survey analysis in this study, questionnaires were used for data collection. The questionnaire consists of three sections:

- First section, letter attachment: a letter to the respondents, appreciating their cooperation and assuring them that all information obtained will be kept confidential.

- Second section, demographic questions: includes questions regarding the location, age, gender, education, and job experiences.

- Third part, studied variables: in this sections questions are asked regarding the effects of organizational behavior in various fields such as innovation orientation, competition orientation, and market orientation

- On competitive advantage building. This part of the questionnaire consists of 24 items. In the following Table 1 the researcher shows the structure of questionnaire.

\section{Validity and reliability of the measurement tool}

In any measurement, despite of precision of measurement tools, there is still a degree of error called measurement error. The researcher should reduce this error and prove the quality of measurements. This requires proving the reliability and validity [3]

Validity: In this study, content validity is used to measure the validity of items (questionnaire, to be more specific). Basically, content validity is a sort of validity often used to examine the components of a measuring tool. If questions of a measuring tool reflect characteristics and special skills that the researcher intends to measure, then content validity of the test is approved. Hence, for content validity (in spite of validity of questionnaires) they were delivered to subject experts, including the supervisor and four executives of related industries (before the pre-study) for their comments and recommendations regarding the questionnaire with respect to the research goals. After receiving back, the questionnaire, the proposed amendments by the experts were considered in order to have full content validity of questionnaire.

\begin{tabular}{|c|c|c|c|}
\hline Main Variable & Description & \# of questions & Resources \\
\hline & Innovation & \multirow[b]{2}{*}{7 items ( 1 to 7 ) } & Chen et al. in 2014 \\
\hline & Orientation & & $\begin{array}{l}\text { Theodosius et al. } \\
\text { in } 2012\end{array}$ \\
\hline & Competitive & \multirow{2}{*}{5 items (8 to 12 ) } & Chen et al. in 2014 \\
\hline & Orientation & & Greenstein in 2008 \\
\hline & Market & \multirow{2}{*}{6 items (13 to 18$)$} & Chen et al. in 2014 \\
\hline & Orientation & & Kirka et al. in 2005 \\
\hline \multicolumn{2}{|c|}{$\begin{array}{l}\text { Competitive advantage building } \\
\text { performance }\end{array}$} & 6 items (19 to 24 ) & Chen et al. in 2014 \\
\hline
\end{tabular}

Table 1: The structure of questionnaire.

Reliability: In this study, as in many other studies, Cronbach's alpha is used to assess the reliability of the measurement tool. Cronbach's alpha is a number between zero and one. Alpha coefficient less than 0.6 indicates poor reliability. Alpha coefficient of 0.7 to 0.8 indicates relatively good reliability, and Alpha coefficient higher than 0.8 indicates high validity of the measurement tool.

$$
\alpha=\frac{J}{J-1}=\left[1-\frac{\sum_{j=1}^{n} S_{j}^{2}}{S^{2}}\right]
$$

Where J=number of questions in the questionnaire, $\mathrm{Sj} 2=$ Variance of answers to questions in J, and S2=Variance of total scores for each subject in all questions.

\section{Analysis method}

In research process, the next step after data collection is data analysis. When we speak of data analysis, the impression is that we only mean statistical analysis of data, while this is not the case. Statistical analysis is only one of the ways for data analysis which is in fact an important one and is applied to research and data with mere statistical aspects. There are many researches that lack statistical aspects and they rely mainly on documents, witnesses, perception, and rational analysis. Such research also follows the complete process of scientific research and includes analysis stage [5].

\section{Descriptive statistics}

In this part of the study, the researcher intends to analyze demographic characteristics such as gender, age, education and purchase experience from the bank primarily to better understand members of the research sample. In the next section of descriptive statistics, the response status is analyzed and each frequency is drawn on a chart. Then, in the final step of this section, central parameters such as mean and variable parameters such as variance and standard deviation, Skewness and kurtosis is explained. All this is done in SPS software.

\section{Inferential statistics}

Data collected in this study is analyzed through Smart PLS software. In general, there are two approaches to estimate relationships in a structural equation model by Hair et al. (1) Methods based on Covariance, and (2) Methods based on Variance. Covariance methods (made with different software such as LISREL and AMOS) focuses on maximizing covariance between structures, while in variance methods (made with software such as Smart PLS) emphasis is on maximizing variance between structures. 
Page 4 of 7

Therefore, in this research the structural equation model method is based on variance, and Smart PLS software is applied to testing research assumptions.

\section{Goodness of fit model}

Ultimately in order to approve target population, goodness of fit model is calculated which includes three parameters: $\mathrm{R}^{2}$ and, finally, GOF. Acceptable limits for each of these parameters are given. For $\mathrm{R}$ square index, 0.19 limit indicates an acceptable fit, greater than 0.25 indicates perfect fit, and over 0.5 indicates that good fit is excellent.

As to $\mathrm{Q}^{2}$, results is that 0.15 indicates an acceptable fit and below that is unacceptable. Over 0.3 indicates perfect fit, and finally over 0.5 indicates that good fit is excellent.

And finally, GOF means total good fit model of the research and is acceptable only if it's more than 0.3 . Total good fit model formula is as follows by Tanenhaus et al. [6].

GOF formula was derived by Tenenhaus et al. [6] as below:

$$
G O F=\frac{\sqrt{\overline{R^{2}} \times \overline{\text { Communalities }}}}{1}
$$

Where communalities are the mean of shared values of each structure and R2 is mean value of R Squares of model's endogenous structures. Wetzels et al. [7] introduced three values of $0.01,0.25$, and 0.36 as weak, average, and strong values for GOF.

\section{Results and Discussion}

In this section, collected data are analyzed through the research tool (questionnaire). The analysis carried out are presented in two separate parts: Part I (descriptive statistics) includes status of demographics attributes; and Part II (inferential statistics) includes analysis of model relationships using SPSS and analysis of structural equation model based on variance (using Smart PLS software, partial least squares) to examine the hypotheses and conceptual model of research.

\section{Demographics attributes}

Demographics attributes of samples such as gender, age, education, work experience, position, institute history, number of staff and central parameters and dispersion of quantitative parameters is discussed in the following section (Table 2).

Describing sample members based on gender: $62 \%$ of samples are men, while $38 \%$ are women.

Describing sample members based on age: Ages 25 to 35 and over 45 are respectively highest $(52.7 \%)$ and lowest $(8.2 \%)$ sample sizes. The remaining $39 \%$ who participated in this study aged between 35 and 45 years old (Table 3).

Describing sample members based on education: People with associate degree and below had lowest frequency $(0 \%)$ and bachelor's degree had highest frequency (75.9\%). 24.1\% of samples had postgraduate studies (Table 4).

Describing sample members based on work experience: $54.5 \%$ of participants had 7 to 14 years of experience and $45.5 \%$ had less than 7 years of experience (Table 5).

\section{Inferential statistics}

Data analysis conducted to test this research is structural equation using Smart PLS software. Structural equation modeling is a statistical

\begin{tabular}{|c|c|c|c|}
\hline Variable & Men & Women & Total \\
\hline Frequency & 108 & 66 & 174 \\
\hline Gender & 62 & 38 & 100 \\
\hline
\end{tabular}

Table 2: Frequency of samples based on gender.

\begin{tabular}{|l|c|c|c|c|c|}
\hline \multirow{2}{*}{ Variablesar| } & \multicolumn{5}{|c|}{ Ages (years) } \\
\cline { 2 - 6 } & Less than $\mathbf{2 5}$ & $\mathbf{2 5}$ to $\mathbf{3 5}$ & $\mathbf{3 5}$ to $\mathbf{4 5}$ & Over $\mathbf{4 5}$ & Total \\
\hline Frequency & - & 92 & 68 & 14 & 174 \\
\hline Percentage & - & 52.8 & 39 & 8.2 & 100 \\
\hline
\end{tabular}

Table 3: Frequency of samples based on age.

\begin{tabular}{|c|c|c|c|c|c|}
\hline \multirow[b]{2}{*}{ Variables } & \multicolumn{5}{|c|}{ Education } \\
\hline & $\begin{array}{l}\text { Associate } \\
\text { degree and } \\
\text { below }\end{array}$ & $\begin{array}{c}\text { Bachelor's } \\
\text { degree }\end{array}$ & $\begin{array}{c}\text { Postgraduate } \\
\text { degree }\end{array}$ & $\begin{array}{c}\text { PhDs and } \\
\text { higher }\end{array}$ & Total \\
\hline Frequency & - & 132 & 42 & - & 174 \\
\hline Percentage & - & 75.9 & 24.1 & - & 100 \\
\hline
\end{tabular}

Table 4: Frequency of samples based on education.

\begin{tabular}{|l|c|c|c|c|c|}
\hline \multirow{2}{*}{ Variables } & \multicolumn{5}{|c|}{ Work experience (years) } \\
\cline { 2 - 6 } & Less than 7 & $\mathbf{7 - 1 4}$ & $\mathbf{1 5 - 2 1}$ & Over 21 & Total \\
\hline Frequency & 79 & 95 & - & - & 174 \\
\hline Percentage & 45.5 & 54.5 & - & - & 100 \\
\hline
\end{tabular}

Table 5: Frequency of samples based on work experience.

modeling which analyzes linear relationship between latent variables and measured variables. In other words, structural equation modeling is a powerful method that simultaneously combines measuring model (confirmatory factor analysis) and structural model (regression and path analysis) with a statistical test. Path analysis, at its best, suggests the possible links between the variables through its main feature which is path diagram, and includes three main steps. The first step is the formation of hypotheses. Second step is selection or development of measures for variables (hypothetical constructs). The third step in the path analysis based on multiple regression analysis is to calculate the statistics that show the strength of the relationship between each pair of variables, and here for each pair of variables in the path analysis, a path coefficient (standardized regression coefficient which is a number between 1 and -1) is obtained. The higher value means stronger relationship between these two variables, and a benefit of path analysis is that it enables the researcher to measure the total effects of one variable on another variable and compare their amounts using path coefficient.

Primary data screening and expressing descriptive statistics: In this stage of research, the researcher is required to screen data as below prior to final analysis to make sure data analysis results are valid and reliable.

- Input data accuracy based on precision in data entry

- Checking data to avoid data loss

- Checking the normality

- Evaluating variables to check linearity between variables

\section{Measurement model assessment of the study}

Assessing the validity of research tools: Structure validity analysis is calculating CR and AVE indices using standardized factor loading obtained from CFA. There are different opinions regarding CR threshold. Standard combined validity offered by Bagozzi and Yi [8] is 0.6 , while Fornell and Larcker [9] in their study emphasized on 0.5 as the level of acceptance for AVE index. 
Analyzing measurement model factor loading show that for all observing variables the factor loading is higher than the set standard. Therefore, none of the questions in the questionnaire are deleted nor adjusted, and all of them will be available in structural equation analysis. Hence, it assures that each observing variable (questions) has an appropriate correlation with its corresponding latent variable (relevant factor) and the structure validity is approved.

Assessing the structural model: In this section, structural model is assessed and the overall study model is fitted. For this purpose, significance and coefficients of research model path is assessed using bootstrap method (consecutive re-sampling) and Student's t-test. In fact, the relation between coefficient of determination and correlation coefficient better shows the index and relations between two variables. This index represents the percentage changes in the function by the independent variable. Coefficient of determination is a number between zero and one. If the coefficient of determination is equal to zero, it means that the regression line hasn't related function dependent variables to independent function. In other words, if there's no change in the dependent variable given by the regression, coefficient of determination is equal to zero. If the coefficient of determination is equal to one, it means that the regression line has related function dependent variables to independent function. In other words, if all changes in dependent variable are yielded by the regression equation, value of coefficient of determination will equal to one and other values will be in between.
$\mathrm{R}^{2}$ Values close to 0.67 are satisfactory, close to 0.33 are normal, and close to 0.19 are weak (Chen). Finally, the ability to predict model is evaluated using nonparametric Stone Geisser nonparametric test. In Stone Geisser test, two values ( $\mathrm{Q}^{2}$ values) are given: CV. Redundancy and CV. Communality. The value of CV. Redundancy simultaneously evaluates both structure model and test model, and the value of CV. Communality evaluates only the test model $[5,10]$. High and positive $\mathrm{Q}^{2}$ values show high prediction abilities, and negative $\mathrm{Q}^{2}$ values show weak estimation of latent variables [7]. Coefficient of determination and $\mathrm{Q}^{2}$ values, path coefficients and T-test model values are given in Figures 1 and 2 respectively.

As presented in Table 6, values of coefficients of determination for latent variables show impacts of independent variables on dependent variables. In fact, it's concluded from values of Table 7 that 0.224 percent of competitive advantage building performance structure changes are made by impacting structure (innovation orientation, competitive orientation, and market orientation). Evaluation of 2 values shows that none of 2 values are negative, and minimum values for prediction are estimated.

And finally, the overall fit of the model is explained where in models based on partial least squares, GOF index is used which needs to be more than 0.3 . This index is calculated using formula for current model as below and shows appropriateness of the overall model.

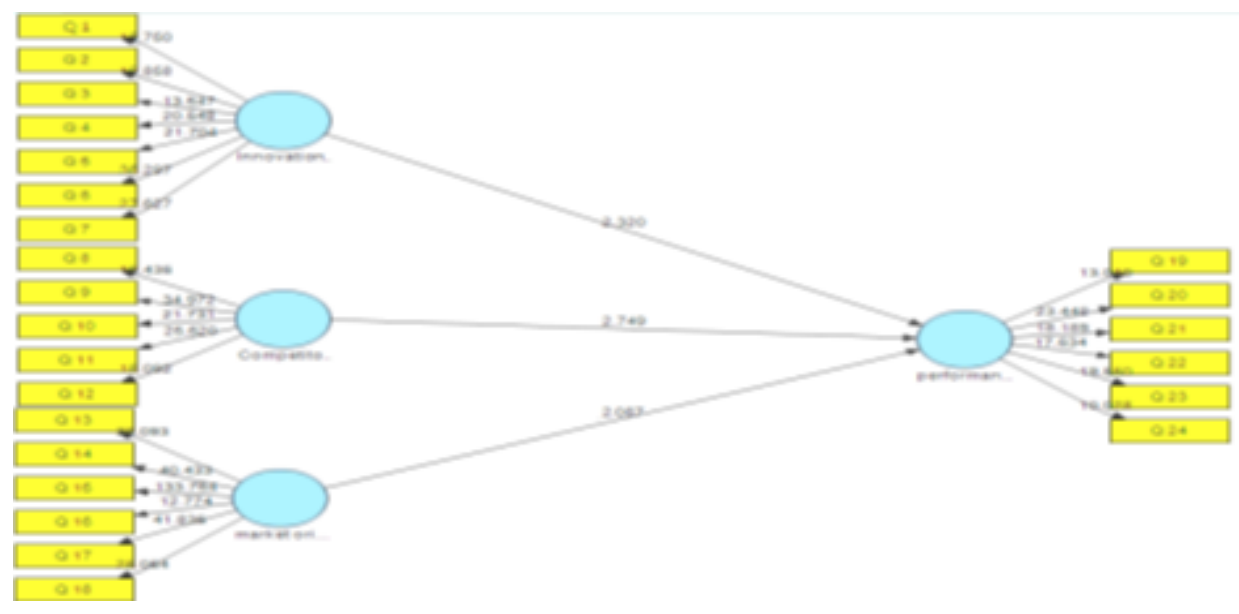

Figure 1: Partial least squares model with significance.

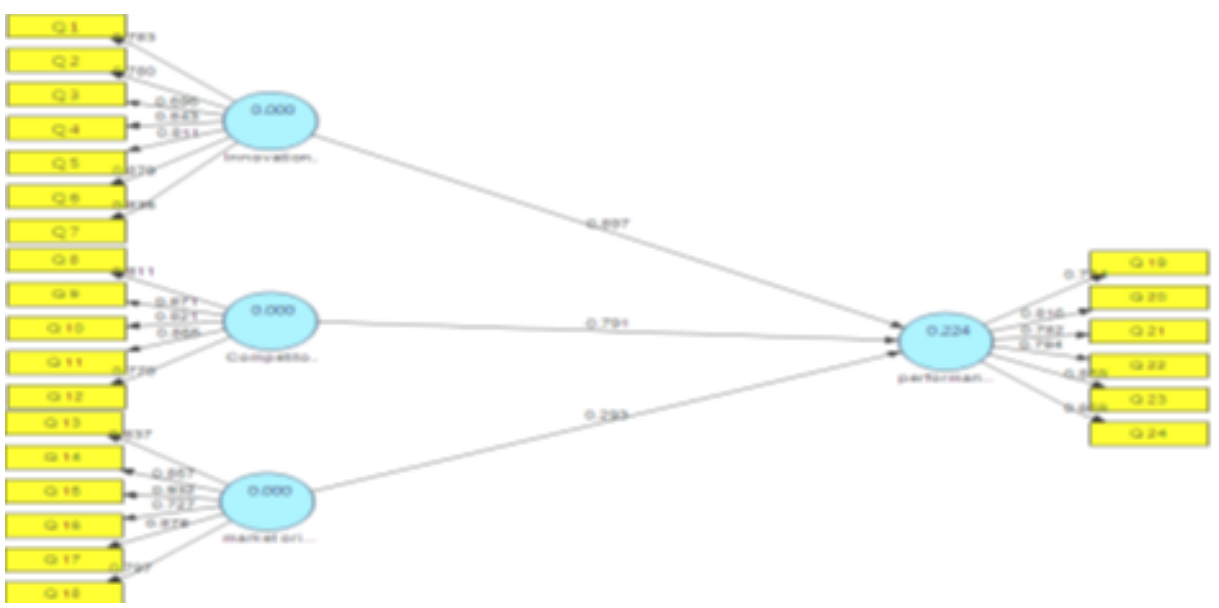

Figure 2: Partial least squares model with standard coefficients. 


\begin{tabular}{|c|c|c|c|c|}
\hline Variable & Average & $\begin{array}{c}\text { Lowest } \\
\text { value }\end{array}$ & $\begin{array}{c}\text { Highest } \\
\text { value }\end{array}$ & $\begin{array}{c}\text { Standard } \\
\text { deviation }\end{array}$ \\
\hline Innovation orientation & 4.014 & 1.0 & 4.41 & 0.858 \\
\hline Competitive orientation & 3.974 & 1.0 & 4.55 & 0.597 \\
\hline Market orientation & 3.841 & 1.0 & 4.70 & 0.780 \\
\hline $\begin{array}{c}\text { Competitive advantage building } \\
\text { performance }\end{array}$ & 3.843 & 1.0 & 4.53 & 0.824 \\
\hline
\end{tabular}

Table 6: Central parameters and dispersion of research variables.

\begin{tabular}{|c|c|c|c|}
\hline Structures & $\begin{array}{c}\text { Coefficient of } \\
\text { determination }\end{array}$ & CV. Red & CV. Com \\
\hline Innovation orientation & - & 0.649 & 0.649 \\
\hline Competition orientation & - & 0.685 & 0.685 \\
\hline Market orientation & - & 0.706 & 0.706 \\
\hline $\begin{array}{c}\text { Competitive advantage building } \\
\text { performance }\end{array}$ & 0.224 & 0.119 & 0.616 \\
\hline
\end{tabular}

Table 7: Study model coefficients of determination.

\begin{tabular}{|c|c|c|c|c|c|}
\hline \multirow{2}{*}{ Assumption } & \multicolumn{2}{|c|}{ Variable } & $\begin{array}{c}\text { Direct path } \\
\text { coefficient } \\
\mathbf{( \beta )}\end{array}$ & $\begin{array}{c}\text { T-test } \\
\text { values }\end{array}$ & Results \\
\cline { 2 - 5 } & Independent & Dependent & Approved \\
\hline 1 & $\begin{array}{c}\text { Innovation } \\
\text { orientation }\end{array}$ & $\begin{array}{c}\text { Competitive } \\
\text { advantage } \\
\text { building } \\
\text { performance }\end{array}$ & 0.897 & 2.32 & Approved \\
\hline 2 & $\begin{array}{c}\text { Competitive } \\
\text { Orientation }\end{array}$ & $\begin{array}{c}\text { Competitive } \\
\text { advantage } \\
\text { building } \\
\text { performance }\end{array}$ & 0.791 & 2.749 & Approved \\
\hline 3 & $\begin{array}{c}\text { Competitive } \\
\text { advantage } \\
\text { building } \\
\text { Orientation }\end{array}$ & 0.293 & 2.087 & \\
\hline
\end{tabular}

Table 8: T-test results: research hypotheses testing.

\section{$\mathrm{GOF}=\sqrt{ }$ Communalities $\times R 2=0.498$}

Testing study's overall conceptual model: The conceptual model analysis applied for this research is structural equation modeling approach using SmartPLS software. Structural model is reported herein. To evaluate significance of model relations, significant coefficient ( $t$-value) is adopted which is provided in Figures for each of the relationships and measurements.

In this part of research, the main research assumptions were tested by path coefficients and t-test. If the value of t-test is bigger than 1.96 for a path, it can be concluded that the path was significant and the assumption is approved with 0.05 error. Table 8 shows results of t-test.

First assumption: Innovation orientation has positive and significant effect on competitive advantage building performance.

Result of partial least square approves this assumption because t-test is equal to 2.32 which is greater than absolute 1.96 , hence, by 0.95 level, above assumption is approved. On the other hand, effect of this assumption is 0.897 , which indicates direct and positive effect of innovation orientation on competitive advantage building performance.

Second assumption: Competitive orientation has positive and significant effect on competitive advantage building performance

Result of partial least square approves this assumption because $t$-test is equal to 2.749 which is greater than absolute 1.96 , hence, by 0.95 level, above assumption is approved. On the other hand, effect of this assumption is 0.791, which indicates direct and positive effect of competitive orientation on competitive advantage building performance.
Third assumption: Market orientation has positive and significant effect on competitive advantage building performance

Result of partial least square approves this assumption because t-test is equal to 2.087 which is greater than absolute 1.96 , hence, by 0.95 level, above assumption is approved. On the other hand, effect of this assumption is 0.293 , which indicates direct and positive effect of competitive orientation on competitive advantage building performance.

\section{Conclusion}

Organizations that are operating in a competitive environment are undoubtedly facing numerous challenges to maintain or improve their position. Actions and behaviors of companies, especially serviceoriented organizations, in improving and strengthening this position is practical and fundamental. The most important measures are strategic approaches and its related actions, including innovation orientation, market orientation, and competitive orientation. Service-orientation companies, including insurance companies, need to adopt correct approaches and communicate with their surrounding environment to develop the basis for understanding and strengthening their performance in competitive markets. Many companies, with respect to competitive orientation, try to gain adequate understanding of their competitor's actions and services and use this knowledge to improve their performance in competitive markets. In addition to that, strengthening innovation orientation is also among those topics that can be very effective in improving the performance of business. This research is conducted among personnel of Saman insurance branches. Reason for choosing this is the importance of organizational behaviors and actions in services market with high competition, such as insurance market. Researcher has gathered 174 questionnaires and used smart PLS software to test research assumptions.

Results of partial least square approves the first assumption of this research: innovation orientation effects competitive advantage building performance, because $t$-test in this assumption is equal to 2.32 which is greater than absolute value of 1.96 and implies that at 0.95 level this assumption is approved. On the other hand, effect of this assumption is equal to 0.897 which shows direct and positive effect of innovation orientation on competitive advantage building performance. Saman Insurance is undoubtedly operating in a very competitive environment. An environment with features such as increased competition, extreme environmental turbulences, technological changes, and environmental uncertainties. These issues have forced Saman Insurance to accept innovation as a main part of its strategy.

Results of partial least square approves the second assumption of this research: Competitive orientation has significant and positive effects on competitive advantage building performance, because t-test in this assumption is equal to 2.749 which is greater than absolute value of 1.96 and implies that at 0.95 level this assumption is approved. On the other hand, effect of this assumption is equal to 0.791 which shows direct and positive effect of competitive orientation on competitive advantage building performance.

Results of partial least square approves the third assumption of this research: Market orientation has significant and positive effects on competitive advantage building performance, because t-test in this assumption is equal to 2.087 which is greater than absolute value of 1.96 and implies that at 0.95 level this assumption is approved. On the other hand, effect of this assumption is equal to 0.293 which shows direct and positive effect of market orientation on competitive advantage building performance. As mentioned, market orientation 
as among important aspects in developing strategic approaches and can strengthen business performance of the organization in the long term. Market orientation is the heart of management and modern marketing strategy. Any business that improves its market orientation will consequently improve its market performance.

\section{Recommendations}

This research recommends that Saman insurance adopts the following strategies:

- Allocating the necessary resources in research and development and increasing support of its operations and functions.

- Implementation and deployment of customer knowledge management systems and organizational knowledge, especially in knowledge of customer and for the customer in order to identify hidden needs and offering new services to meet customer needs.

- Creating communication networks with competitors in order to increase and improve understanding of actions and aligning these actions with competitor's decisions.

- Using competitor's potentials through cooperation with competitors for better performance in competitive markets.

- Understanding and evaluating actions and strategies of competitors in the insurance market.

- Considering online marketing concepts and online strategies in order to increase trust and positive visualization in competitive markets to increase customer purchase intention.

- Using The use of online social media to enhance customer knowledge system and improve brand awareness, and to gain better knowledge of customers and competitors to improve business accountability.

- Strengthening information systems and technology infrastructures in the organization in order to speed up and strengthen coordination between different organizational units.

\section{References}

1. Olson EM, Slater SF, Hult GTM (2005) The performance implications of fit among strategy, marketing organization structure and strategic behavior. J Market 69: 49-65.

2. Jaworski BJ, Kohli AK (1990) Market orientation: The construct, research propositions, and managerial implications. J Market 54: 1-18.

3. Zohreh S (2010) Research methods in behavioral sciences, Agah Publications Tehran, (9th edn). pp. 1-177.

4. Sarokhani B (1991) Research methods in social sciences, humanities and economic studies research Institute, Tehran, (7th edn). pp. 70-80.

5. Hafeznia MR (1998) Introduction to research methods in humanities. Samt publications, Tehran (8th edn). pp. 210-220.

6. Tenenhaus M, Vinzi VE, Chantelinc YM, Lauro C (2004) PLS patch modeling Comput Stati Data Anal 48: 159-205.

7. Wetzels M, Odekerken-Schroder G, Van Oppen C (2009) Using PLS path modeling for assessing hierarchical construct models: Guidelines and empirical illustration. MIS Quarterly 33: 177-195.

8. Bagozzi RP, Yi Y (1988) On the evaluation of structural equation. J Acad of Market Sci 16: 74-94.

9. Fornell C, Larcke DF (1981) Evaluating structural equation models with unobservable variables and measurement error. J Market Res 18: 39-50.

10. Haier O, Tjemkes, B, Henseler J (2011) A model of response strategies in strategic alliances: A PLS analysis of a circumplex structure. Long Range Planning 45: 424-450. 